\title{
A FAMÍLIA (EN)CONTRA A ESCOLA: POBREZA, CONFLITOS E OBRIGATORIEDADE ESCOLAR NAS MINAS GERAIS DO SÉCULO XIX
}

\author{
Fabiana da Silva Viana* \\ lattes.cnpq.br/0399569574635663
}

\begin{abstract}
Resumo: Neste artigo dedico-me ao estudo das relações estabelecidas entre pais de família, professores primários e autoridades locais em Minas Gerais, nas primeiras décadas do século XIX. Para tanto, recorri a um grande número de documentos produzidos por presidentes de província, bem como pela Assembleia Legislativa e pelas autoridades responsáveis pela fiscalização das escolas primárias mineiras. Já no alvorecer do século XIX, o desejo de civilizar e formar o cidadão trabalhador motivara a elaboração de dispositivos legais voltados à organização e ampliação do serviço de instrução pública. Foi neste contexto que intelectuais e políticos defenderam a educação das crianças e a generalização da instrução pública primária, considerando-as como as medidas mais adequadas à formação da nação brasileira. Em Minas Gerais, o que se observa a partir daí é a intensificação, nos discursos de intelectuais e dirigentes, de uma preocupação com a infância e sua preparação para a vida adulta. Preocupação, contudo, alicerçada em uma percepção um tanto preconceituosa e negativa em relação à moralidade das famílias mineiras e na compreensão de que elas eram incapazes de zelar pelo futuro de suas crianças. O que tais intelectuais e políticos não esperavam, contudo, é que os pais de família resistissem a essas representações, demonstrando a fragilidade das críticas que lhes eram dirigidas e o caráter ainda incipiente das ações do governo do Estado.
\end{abstract}

Palavras-chave: Instrução pública; Obrigatoriedade escolar; Relação famíliaescola.

\section{FAMILY ENCOUNTER SCHOOL: POVERTY, CONFLICTS AND COMPULSORY SCHOOL IN MINAS GERAIS OF THE 19TH CENTURY}

Abstract: In this paper I study the relations established among parents, primary teachers and local authorities in the first decades of the nineteenth century in Minas Gerais. To do so, I relied on a large number of documents produced by provincial presidents, by the Legislative Assembly and by the authorities responsible for super-

\footnotetext{
* Doutora em Educação. Docente na Universidade do Estado de Minas Gerais (Brasil). Contato: fabianadasilvaviana@gmail.com.
} 
vising primary schools in Minas Gerais. In the late nineteenth century, the desire to civilize and to form the working citizens motivated the elaboration of legal devices whose aim was to organize and to expand the public education service. It was in this context that intellectuals and politicians defended the children's education for all and the generalization of primary public education as the most appropriate measures for the formation of Brazilian nation. In Minas Gerais, what is observed from there is the intensification in the discourses of intellectuals and leaders of a concern with childhood and its preparation for adult life. This concern was based on a prejudiced and negative perception of the morality of Minas families and on the understanding that they were unable to take care of the future of their children. What such intellectuals and politicians did not expect, however, was the resistance of the parents to these representations. They demonstrate the fragility of the criticisms directed against them and the incipience of the state government policies.

Keywords: Public education; Compulsory school; Family-school relationship.

$$
\text { * } * *
$$

Atualmente é comum ouvirmos dos profissionais das escolas que um dos grandes problemas enfrentados no trabalho com os alunos tem sido o descompromisso de pais e o pouco envolvimento das famílias. Além da falta de cuidados básicos - seja com a alimentação, o vestuário ou a saúde -, muitos pais são acusados de não incentivarem seus filhos a manterem uma frequência regular às aulas, de não colaborarem na realização das tarefas enviadas para casa, de não comparecerem à escola quando são solicitados, etc. Em outra direção, não é raro encontrar pais que se queixam de professores; que procuram a coordenação das escolas para reclamarem de atitudes e métodos empregados no ensino e disciplinamento de seus filhos. Nestas e em diversas outras situações é possível perceber a existência de um conflito marcado por interesses e expectativas divergentes acerca da educação escolar; ou seja, os pais, os professores, os pedagogos e os gestores possuem maneiras diversas e, muitas vezes, divergentes de compreender essa instituição e suas atribuições. Um olhar histórico e cuidadoso dessa relação - entre os pais e os profissionais da escola - permite perceber que, duzentos anos depois da implantação de um sistema brasileiro de ensino, há ainda uma tensão em torno da de- 
finição do papel a ser desempenhado pela escola e pelas famílias na formação das novas gerações.

Neste artigo dedico-me ao estudo destas relações. Dedico-me, mais particularmente, ao estudo das relações travadas entre pais de família, professores primários, fiscais e políticos em Minas Gerais, entre os anos de 1820 e $1850 .{ }^{1}$ Foi neste momento que dirigentes políticos e legisladores buscaram instituir as aulas de instrução pública primária. Até o ano de 1822 as escolas eram geridas pelo governo português e tinham seus professores nomeados pelo rei, daí a designação de "escolas régias". A partir de 1822 é possível encontrar na documentação governamental principalmente nas leis - uma nova designação para essas instituições: "escolas de primeiras letras", "escolas públicas de instrução primária”, "escolas da nação". 2 O uso corrente destas novas denominações revelava as expectativas de alguns grupos sociais com a instituição escolar. Tais instituições deixavam de ser, então, propriedade de um rei e passavam a pertencer à nação brasileira, assumindo o papel precípuo de produzir mentalidades e propagar as maneiras mais adequadas de participação dos cidadãos naquela "civilização principiante". 3

Como parte de um conjunto de medidas ligadas à formação de uma nação independente e livre dos "grilhões" do passado, a elite política nacional se ocupou da institucionalização das aulas de instrução primária. Uma primeira iniciativa, nesse sentido, foi a regulamentação de um serviço de instrução pública e a decorrente tentativa de padronização de conteúdos e métodos de ensino, além de formas de contratação e pagamento de professores. A primeira lei nacional a este respeito foi promulgada em 15 de outubro de 1827. Nela ficou estabelecido que os professores primários deveriam ensinar os rudimentos da leitura, da escrita e da aritmética, a gramática da língua nacional, os princípios da moral cristã e

\footnotetext{
${ }^{1}$ Este capítulo foi produzido a partir de projeto de pesquisa desenvolvido na Faculdade de Educação da Universidade do Estado de Minas Gerais, em Belo Horizonte.

2 Refiro-me respectivamente à Lei Imperial de 15 de outubro de 1827 e à Lei Mineira n. 13, de 07 de abril de 1835. Disponível em: <www.camara.gov.br >.

3 Esta expressão foi usada por José Agostinho Vieira, no oficio em que agradecia sua nomeação para o cargo de delegado do $5^{\circ}$ Círculo Literário. Correspondências, 20/05/1835. APM SP PP 1/42, caixa 2, pacotilha 43.
} 
da doutrina católica, "proporcionados à compreensão dos meninos”. A lei orientava aos professores, ainda, que adotassem nos exercícios de leitura realizados em sala de aula, preferencialmente, a "Constituição do Império e a História do Brasil".4

O governo que se instaurava, além de promover mudanças quanto à designação das escolas e tentar uniformizar o ensino, responsabilizou os dirigentes das províncias pela organização e manutenção do serviço de instrução pública primária. 5 A partir de então, tanto em Minas Gerais como em outras províncias, autoridades políticas incorporaram aos seus discursos argumentos em defesa do aumento do número de escolas, da preparação de professores para a utilização dos métodos mais "modernos" de ensino e da distribuição de materiais às escolas e aos seus alunos mais pobres. Na província de Minas Gerais, os legisladores se dedicaram, a partir do ano de 1835, à elaboração de um certo conjunto de dispositivos legais. Destacam-se desse conjunto a Lei Mineira $n$. 13 e seu Regulamento $n$. 3, onde se definia que somente as pessoas livres poderiam frequentar as escolas públicas e que a instrução primária seria organizada na forma de dois "graus". Nas escolas de segundo grau, criadas em cidades e vilas, seriam ensinadas a leitura, a escrita, a aritmética até proporções e as "noções gerais" dos deveres morais e religiosos. Nas escolas de primeiro grau, instaladas em localidades onde pudessem ser frequentadas por pelo menos vinte e quatro alunos, seriam ensinadas a leitura, a escrita e as quatro operações. Além dessas duas modalidades de escolas primárias, poderiam ser criadas "Escolas para meninas" nos lugares onde houvesse as de segundo grau e onde pudessem ser frequentadas por pelo menos vinte e quatro alunas.

Com relação aos professores, a lei determinava que todos aqueles que não tivessem suas aulas frequentadas pelo número estipulado de

\footnotetext{
4 Refiro-me à Lei Imperial de 15 de outubro de 1827, Art. 6.

5 Refiro-me ao Ato Adicional, de 12 de agosto de 1834 que, dentre outras coisas, atribuiu aos governos provinciais a competência de legislar sobre a divisão civil, judiciária e eclesiástica; a polícia e economia dos municípios; a repartição e fiscalização das rendas públicas provinciais e municipais; a criação e supressão de empregos públicos; as obras públicas, as estradas e a navegação; as casas de prisão e socorro; a instrução pública primária e secundária.
} 
alunos seriam demitidos; exceto, evidentemente, quando a falta de frequência fosse causada pela falta de habitantes. Poderiam ser nomeados professores todos os cidadãos brasileiros ou estrangeiros, com mais de dezoito anos, com bom comportamento e com os conhecimentos exigidos pela lei. Para concorrerem às cadeiras de instrução pública primária, os candidatos precisariam comprovar sua morigeração com "documentos fidedignos, em que não só se declar[asse] expressamente que o pretendente é de vida regular e próprio para o ensino da mocidade, mas também onde residiu os quatro últimos anos e que durante esse tempo não foi condenado" pelos crimes de "furto ou roubo". 6 Juntamente com a apresentação desses atestados, os candidatos deveriam ser submetidos a um exame público, na presença de autoridades competentes e designadas pelo governo da província. Estas autoridades seriam os delegados literários, função instituída a partir das leis promulgadas em 1835, que deveriam se ocupar tanto do exame dos candidatos ao magistério como da fiscalização das escolas.

Uma última ordem expressa nesse documento e que teve significativa repercussão para o governo e para alguns dos habitantes da província foi a obrigação imposta aos pais de família, que a partir desse momento deveriam "dar a seus filhos a instrução primária do $1^{\circ}$ grau ou nas Escolas Públicas, ou particulares, ou em suas próprias casas”. ${ }^{7}$ Esta obrigação se aplicava aos pais de família que tivessem filhos entre 8 e 14 anos de idade e precisaria ser cumprida para que a multa prevista não fosse cominada. As reações que esta imposição incitou entre professores e pais de família foram descritas pelos delegados literários e povoaram os relatórios por eles enviados ao governo mineiro, entre os anos de 1835 e 1850. ${ }^{8}$ Minha pretensão neste capítulo, portanto, é discorrer sobre estas reações, ou seja, sobre os conflitos decorrentes das imposições legais e

\footnotetext{
${ }^{6}$ Lei Mineira n. 13, de 28 de março de 1835 . Art. $16^{\circ}$.

7 Lei Mineira n. 13, de 28 de março de 1835 . Art. $12^{\circ}$.

8 Cabe ressaltar que em outubro de 1848, por meio da Lei Mineira n. 435, foi criado o cargo de diretor geral da instrução pública. A partir desta data os delegados literários deveriam se corresponder diretamente com essa autoridade, sendo desnecessário, portanto, que continuassem a enviar seus relatórios aos presidentes de província ou à secretaria do governo.
} 
sobre os sentidos produzidos, tanto por dirigentes políticos e professores como por pais e mães de família, a respeito da educação escolar, pública e primária que se instituía.

\section{A educação da infância e as famílias mineiras}

Michelle Perrot (1991a) ressalta a importância que as elites políticas e intelectuais conferiram às famílias e à educação da infância na Europa, durante o século XIX. Segundo a autora, após a Revolução Francesa, o pensamento liberal francês defendeu a família como sendo a chave para a felicidade individual e para o bem público. A revitalização da sociedade civil se daria, sobretudo, por meio da felicidade das famílias. Estas eram representadas como sendo células reprodutoras, pois produziam as crianças e proporcionavam-lhes a primeira forma de socialização, zelavam pela sua pureza e saúde e transmitiam-lhe os valores simbólicos e a consciência nacional. Logo, eram criadoras da cidadania e da civilidade. A intervenção dos poderes político e religioso sobre a vida privada das famílias justificava-se com a compreensão de que "o filho não pertence apenas aos pais: ele é o futuro da nação e da raça, produtor, reprodutor, cidadão e soldado do amanhã. Entre ele e a família, principalmente quando esta é pobre e tida como incapaz, insinuam-se terceiros: filantropos, médicos, estadistas que pretendem protegê-lo, educá-lo, disciplinalo" (PERROT, 1991b, p. 148). O Estado se interessaria, assim, por todas as famílias, mas sua intervenção estaria direcionada em primeiro lugar àquelas pobres, consideradas incapazes de desempenhar seu papel com relação à educação dos filhos.

Também no Brasil, a defesa da família esteve relacionada ao aparecimento de novas configurações sociais e à difusão de padrões e códigos civilizados. De acordo com Luciano Raposo de Almeida Figueiredo (1997), já no século XVIII, em Minas Gerais, a Igreja e o Estado colonial adotaram a política comum de defesa do casamento e de combate às uniões consensuais. As especificidades que marcaram a ocupação do territó- 
rio mineiro imprimiriam sobre as famílias uma organização diferenciada daquela preconizada pelas autoridades políticas e religiosas. Para aqueles que se ocupavam da mineração e precisavam se deslocar constantemente, o estabelecimento de laços familiares mais estáveis nem sempre era possível. Além disso, a pobreza da maior parte das famílias e as altas taxas cobradas pela Igreja inviabilizava a celebração e oficialização dos casamentos. O comportamento indisciplinado dos clérigos e o domínio exercido pelos proprietários sobre a vida de seus escravos impediam, ainda, à Igreja estender a toda a população suas regras matrimoniais. Estas foram algumas das razões para que o concubinato se tornasse a relação típica dos setores intermediários e dos grupos populares em Minas Gerais (FIGUEIREDO, 1997, p. 37).

A política familiar adotada pela Igreja e pelo Estado, de acordo com Figueiredo, tinha como objetivo a normalização dos grupos sociais e sintonizava-se ao desenvolvimento da mineração e ao fortalecimento da administração colonial. Como podemos verificar na troca de correspondências entre D. João V, rei de Portugal e D. Lourenço de Almeida (1721), governador da capitania, para o Estado colonial o crescimento político da região dependia da sedentarização da população e, concomitantemente, de sua condição matrimonial.

[...] procureis com toda diligência possível para que as pessoas principais, e ainda quaisquer outras tomem o estado de casados e se estabeleçam com suas famílias reguladas na parte que elegerem para sua população, porque por este modo ficarão mais obedientes as minhas reais ordens, e os filhos que tiverem do matrimonio os farão ainda mais obedientes, e vos ordeno me informeis se será conveniente mandar que os casados possam entrar na governança das Câmaras das Vilas. (CARVALHO, 1933, p. 350$)$.

Diante do rápido crescimento demográfico, da ameaça representada pela fuga de escravos e dos conflitos cotidianos, o controle das populações seria condição essencial para garantir a transferência de rendas da capitania mineira ao Estado português. Nas palavras de Figueiredo (1997, p. 25), “a expansão das famílias legítimas, peça vital da paz social que deveria sustentar o funcionamento do sistema colonial, passaria des- 
de então a se constituir como um dos objetos centrais da ação do Estado”.

Nas primeiras décadas do século XIX, com o movimento de consolidação do Estado Nacional Brasileiro, as autoridades provinciais se dedicaram ao controle e ordenamento da "inquieta e heterogênea" (DUARTE, 1995, p. 43) população mineira, promovendo, dentre outras medidas, o recenseamento da população, o mapeamento da província, a construção de estradas e a nomeação de diversos fiscais e funcionários públicos. Reiterando o discurso dos dirigentes mineiros, o jornal $O$ Universal publicava uma série de artigos desqualificando os cuidados e a educação oferecida nas casas de família. 9 Nesses artigos vemos a utilização de um conjunto de referências para designar a "boa" e a "má" educação e, ainda, orientações endereçadas aos pais e mães de família destacando a importância da educação escolar. Além de orientações como essas, alguns articulistas contrapunham a educação condescendente de muitos pais de família à "educação vigilante" e afirmavam ser a infância o momento de aprendizagens que perdurariam por toda a vida.

Luciano Mendes de Faria Filho (1998; 1999) e Mônica Yumi Jinzenji (2002) identificaram nas falas dos presidentes da província e em artigos do Universal, a veiculação de um discurso a respeito das limitações das famílias mineiras para cuidar da infância. De acordo com os autores, a desqualificação produzida acerca das famílias teria permitido não só a elaboração de leis, como aquela que prescrevia a obrigatoriedade da instrução primária, mas a legitimação da escola como local especificamente designado à formação do adulto civilizado. Para Marcilaine Soares Inácio (2003), essa mesma representação a respeito das famílias mineiras, teria motivado a crescente preocupação das autoridades provinciais com a habilitação dos professores que ocupariam as cadeiras de instrução pública primária. Ora, se aquelas famílias não compartilhavam dos códigos necessários às novas configurações sociais, caberia aos professores primários instruir a mocidade, ensinando-lhe, além da leitura, escrita e contas, os deveres morais, civis e religiosos.

9 O jornal $O$ Universal foi publicado entre os anos de 1825 e 1842, na cidade de Ouro Preto. De tendência liberal moderada, ele foi um dos periódicos mineiros mais longevos, na primeira metade do século XIX. 
A incapacidade impingida aos grupos familiares pelas elites locais relacionava-se, de modo geral, à desqualificação produzida acerca da população mineira. O que se fazia, sobretudo, pela associação entre imoralidade e as características étnico-raciais da população. Segundo Martins (1990), entre os anos de 1833 e 1835, 33,3\% da população mineira era composta de escravos. Com relação à população livre, a autora ressalta que $45,2 \%$ eram pardos, $43,8 \%$ eram brancos e $11 \%$ eram pretos.

Além das estigmatizações produzidas acerca de sua cor, a população mineira era inferiorizada pelos seus hábitos e crenças e pelos cuidados dirigidos à infância. O autor do artigo Sobre a má criação, publicado no Universal, no dia 13 de abril de 1840, atribuía à influência de escravos, a imoralidade e o pouco respeito que a mocidade dirigia aos mais velhos. Para o autor, "as brutais maneiras, as grosserias, os vícios dessa raça infeliz, insensivelmente se tem inoculado em o nosso povo, e eis o gérmen da nossa tão geral imoralidade”. O desprezo aos preceitos da religião e o abandono do "temor a Deus" contribuíam para a "vasta" e "lamentável” falta de educação e para o descomedimento dos comportamentos juvenis. Nesse sentido, o autor relatava situações em que presenciou a "má criação" de filhos:

As meninas da sua parte também vão-se adestrando no espírito de insubordinação. D. Adelina já arrebita o narizinho, já trombeja quando a repreendem, e na presença de seus progenitores canta com todo desembaraço

Um pai não pode privar

A filha de querer bem:

Se as leis dos pais são sagradas, As de Amor mais força tem.

Que belo! Que menina espirituosa! Todos a denominam uma jovem sentimental, e com grande aptidão para filosofia, mas eu, que já pendo para velho, e conseguintemente rabugento, digo, que a Sra. D. Adelina é uma completa malcriadinha, e com aptidão para outras prendas, que não convém declarar. Yáyá domdom é assomada, caprichosa, respondona para seus pais: se lhe embargam qualquer vontade, quer deitar as casas abaixo com gritos, ou amua-se a um canto, dardejando de redor olhaduras, que bem patenteiam o rancor, que lhe rala o coraçãozinho: a pascácia da mãe apenas diz - esta menina tem força de gênio é de muitos sentimentos -; eu porem dir-lhe-ia com o de- 
vido respeito "a sua yáyá domdom, minha senhora, o que tem de muito é má criação.” (O UNIVERSAL, 13/4/1840).

"Assomada, caprichosa e respondona", assim foi caracterizada Adelina. Ao contrário da mãe, para quem o comportamento da filha era expressão da "força do gênio" e de exaltados sentimentos, o autor do artigo destacava seu "espírito de insubordinação" e sua "má criação". Como tantos outros artigos, Sobre a má criação falava sobre a "educação indulgente" atribuída aos pais de família e alertava os leitores para as consequências futuras dessa mesma educação. As famílias deveriam assumir, no pensamento desse autor, a responsabilidade sobre a condução das novas gerações, ensinando-lhes quais os papéis sociais a serem assumidos. As proposições de Norbert Elias ajudam-nos a pensar esse novo encargo atribuído às famílias mineiras. Para o autor, ao longo do processo civilizador, novas redes de interdependência foram sendo construídas, em resposta à consolidação de novas configurações sociais. Enquanto forças políticas e econômicas organizavam-se na forma dos Estados nacionais, outras configurações sociais, como a família e a escola, tinham seus papéis redefinidos; ou seja, a consolidação dos Estados nacionais demandou a construção e legitimação de instituições destinadas à difusão das civilidades e à formação das novas gerações.

Os articulistas defendiam, nessa perspectiva, um modelo de organização familiar em que o exercício da autoridade do pai de família e os exemplos continuados do pai e da mãe seriam necessários para que os filhos adquirissem bons hábitos e disposições para a virtude. Eles recorriam, ainda, ao dever do amor recíproco entre pais e filhos e reafirmavam que a "futura felicidade" dos filhos dependeria dos cuidados que lhes fossem dirigidos na infância. Como dizia o autor do artigo Da Educação, publicado no dia 06 de janeiro de 1841,

Aquele, que sentir arder em seu peito o amor paternal, ou o cuidado de que seus filhos tenham para o futuro um modo de vida decente, e que possam concorrer para o bem da sociedade geral, fazendo-se dela dignos membros, deve empregar todo o seu empenho, e autoridade de pai, para que de tenra idade os filhos se vão habituando a práticas de ações justas, e honestas [...]. Só na infância poderão esses filhos contrair bom habito, e por con- 
seguinte os meios de futura felicidade; sendo que ideias verdadeiras, inspiradas constantemente pelo pai, e ajudadas por exemplos continuados e interruptos formem neles acertadas disposições para a virtude. (O UNIVERSAL, 6/1/1841).

Nesse mesmo artigo, contrapondo os efeitos da "má educação" aos resultados da "boa educação", o autor enumerava quais ensinamentos os pais e mães de família deveriam transmitir aos seus filhos:

Portanto é incontestável a vantagem resultante da boa educação dos filhos. É ela que forma o homem para a sociedade. Se for boa, seremos um bom cidadão: se má, um perverso. Os filhos bem educados, e constituídos independentes por qualquer gênero de vida seguro, prometem a velhice do pai consolador animo; aliviam muitas vezes a orfandade de seus irmãos; acodem à pátria com seu auxilio: e no caso contrário, amarguram muitas vezes os últimos instantes de um velho miserável, pai infeliz, de uma mãe isolada. Pezão sobre a pátria, ofendendo-a com crimes, e atentados horrorosos. [...] Estes terríveis efeitos da má educação sirvam de advertir-nos incessantemente do dever rigoroso, que tem todo o pai de guiar seu filho pela estrada da honra, habituando-o às boas ações, fazendo o fugir das más, inspirando lhe sentimentos de religião, de amor a pátria, de respeito para com as leis, para com os maiores, observando seus passos, chamando-o a seus deveres, tirando-o do ócio, origem fértil dos vícios: ensinando lhe o trabalho, instruindo o em princípios sãos, guiando-o em fim pelo caminho da virtude, e formando um cidadão completo. (O UNIVERSAL, 6/1/1841).

O "bem da sociedade geral" dependia da educação recebida nos lares e a felicidade individual ligava-se, por uma "regra geral", a essa mesma educação. Nesse sentido, as famílias deveriam constituir-se como locais por excelência de transmissão dos valores morais, religiosos e civis. Parafraseando Segalen (1999, p. 18), a família passou a ser caracterizada como o local da ordem e como detentora de um poderoso modelo normativo. Por meio dela deveriam ser forjados os valores necessários à realização individual; valores estes decorrentes de "virtudes morais que foram sendo inculcadas ao longo de um prolongado processo de socialização”.

O debate sobre a importância da família no cuidado e educação das novas gerações poderia, ainda, fazer-se numa direção distinta das exortações sobre as especificidades da infância e o necessário cuidado de seu 
desenvolvimento físico e moral. Em um dos artigos publicados no Universal podemos encontrar orientações sobre o dever dos pais no acompanhamento da vida escolar de seus filhos. Em Considerações sobre a educação, tanto científica como popular; tanto publica como pratica, publicado no dia 15 de janeiro de 1840, dizia-se que a educação deveria ser a pública: a "regularidade que caracteriza a educação pública, a superioridade (ao menos presuntiva) dos mestres, a emulação dos alunos" eram vantagens sem precedentes. No entanto, os pais não poderiam se limitar apenas a enviar os meninos às aulas primárias, eles deveriam também acompanhar o desempenho escolar e cuidar, cotidianamente, do desenvolvimento intelectual de seus filhos.

Nas classes inferiores da sociedade os pais geralmente mandam os filhos para as escolas, e julgam-se dispensados de todo o cuidado da educação: os indivíduos abastados chamam mestres particulares, e pensam que fazem os sacrifícios, que demanda este modo de instrução, tem feito tudo. São dois erros: o pobre fez pouco, por que deve além disso vigiar e inquerir sobre o grau de aproveitamento de ensino em que vai o filho, e dar-lhe mais e mais em casa a educação moral; o opulento enganou-se também querendo criar o filho para viver no mundo, e cercando-o ao mesmo tempo dos melindres e concessões que caracterizam a educação particular. [...] os meninos só estão na escola algumas horas do dia; e por isso as obrigações da educação caseira são contínuas. Todo pai e toda mãe que cessa de seguir com o coração e com a alma o desenvolvimento intelectual e moral de seus filhos na primeira idade, de algum modo se separa deles, e por mais cheia de consciência que seja a educação pública, o homem que na sua mocidade foi privado dos benefícios da educação doméstica o dá a perceber em todo o tempo; há certas afeições que o seu coração ignora, hábitos que nunca toma, virtudes que não pode adquirir, gozos morais que não experimenta. Pais, e mães de família, atentai bem nisto; é uma espécie de crueldade dar a existência e recusar a educação; por que esta última será manancial de boas ações para vós, e de prosperidades certas para os vossos filhos. (O UNIVERSAL, 15/1/1840).

A ênfase desses artigos estava em instruir os leitores a respeito das responsabilidades paternas e maternas. Para isso os autores recorriam ao "amor paternal" e buscavam sensibilizar os pais e educadores afirmando, como vimos na citação, ser uma crueldade negar aos filhos a "boa educa- 
ção”. As experiências e aprendizagens provenientes de uma educação exemplar garantiriam não só a realização individual e um modo de vida "decente" no futuro, mas o respeito aos mais velhos e o "amor" à pátria. Legisladores, políticos e intelectuais mineiros viam a família, portanto, como um modelo normativo capaz de exercer "o controle socialmente exigido dos impulsos, e do comportamento dos jovens" (ELIAS, 1994, p. 187). Nesta perspectiva, podemos perceber que as elites políticas e intelectuais não tencionavam simplesmente desqualificar as famílias, mas procuravam atribui-lhes uma nova qualificação. Como destaca Cynthia Greive Veiga (2003, p. 44), havia o interesse em qualificá-las para participar "de um imaginário de sociedade". A dispersão da população pelo território, as constantes agitações sociais e as disputas locais de poder ameaçavam a união e integridade do Império; era necessário criar uma linguagem comum e pontos de referência que orientassem os indivíduos a respeito do lugar que deveriam ocupar nessa "civilização principiante". Por isso, deveriam ser instituídos modelos e representações acerca da família e de seus membros: o "bom pai”, a "mãe amorosa e terna", o filho obediente e o cidadão civilizado.

$\mathrm{O}$ interesse em atribuir uma nova qualificação às famílias mineiras ligava-se, também, à percepção de que a infância seria o momento de formação do caráter. Expostas às ameaças do mundo que as cercavam e suscetíveis às más influências, as crianças precisavam desde tenra idade aprender as virtudes e os bons hábitos. Assim, para a formação do futuro cidadão e do adulto civilizado importava orientar os pais sobre as melhores maneiras de cuidar da infância, auxiliando-os quanto ao seu desenvolvimento físico, moral e intelectual. E estas orientações poderiam, inclusive, assumir o caráter de prescrições legais, como determinava o art. 12 da Lei Mineira n. 13 sobre a obrigatoriedade da instrução primária.

\section{A pobreza dos alunos e de suas famílias}

As estigmatizações produzidas acerca da população mineira justificaram a intervenção dos poderes públicos sobre a vida privada das famí- 
lias. Nesta perspectiva, como Luciano Mendes de Faria Filho e Irlen Antônio Gonçalves (2004) compreendo que a obrigatoriedade da instrução primária incidia mais diretamente sobre as famílias pobres, uma vez que elas eram caracterizadas como indigentes e também, por isso, como "desleixadas, ignorantes e desconhecedoras" dos benefícios da instrução pública elementar. No entanto, cabe salientar que pais e mães não estiveram passivos frente às iniciativas ordenadoras do governo provincial. $\mathrm{Na}$ documentação com a qual trabalhei, identifiquei diferentes posicionamentos com relação à obrigatoriedade da instrução primária e manifestações de professores e delegados em defesa das famílias mineiras. Embora essas informações tenham sido registradas nos relatórios dos delegados literários, foi possível verificar a dinâmica tensa e conflituosa que envolvia as famílias, os mestres de primeiras letras e as prescrições legais.

A Lei Mineira n. 13 determinava que:

Art. $12^{\circ}$. Os Pais de Famílias são obrigados a dar a seus filhos a instrução primária do $1^{\circ}$ grau ou nas Escolas Públicas, ou particulares, ou em suas próprias casas, e não os poderão tirar delas, em quanto não souberem as matériais próprias do mesmo grau. A infracção deste Artigo será punida com multa de dez a vinte mil réis, uma vez que aos infratores se tenham feito três intimações no espaço de seis meses, e não tenham eles apresentado razões, que justifiquem o seu procedimento, ou as apresentadas tenham sido julgadas inatendíveis pelo Governo em vista de informações dos Delegados. Nas reincidências a multa será dobrada. Considere-se reincidência a continuação da falta dois meses depois da condenação.

Art. $13^{\circ}$. A obrigação imposta no Artigo precedente aos Pais de famílias começa aos oito anos de idade dos meninos; mas estende-se aos que atualmente tiverem quatorze anos de idade.

Conforme a discussão realizada, algumas perguntas podem ser feitas: qual significado teve a obrigatoriedade da instrução primária para os pais de família e para os próprios professores e delegados literários? Como os habitantes das diversas povoações reagiram diante da possibilidade dos professores denunciarem sua omissão no cumprimento da lei? Como os delegados iriam comprovar as denúncias feitas pelos professores e como iriam fiscalizar o ensino que acontecia nas casas e fazendas? 
Como multar pais de família diante das contingências sociais que caracterizaram o modo de vida da população mineira? Acerca desta última questão, delegados e professores queixaram-se com as autoridades provinciais dizendo ser a pobreza dos alunos o maior obstáculo para o aumento da frequência escolar. Segundo o professor Antonio Emilio Gomes, mesmo com limitados ordenados, se via "na dura necessidade de fornecer a muitos Alunos miseráveis tinta, papel, Cartas e traslados".10 Da mesma forma, o professor Manoel Pereira de Moraes dizia estar distribuindo aos seus alunos objetos escolares, porque os pais, "quase todos são tão pobres, que é impossível poderem comprar papel, tinta e penas".11 O professor público da escola primária de Minas Novas também informava "que os pais ou educadores, alguns por desleixo, ao maior número por pobreza destratam seus filhos, e sobretudo a falta de adiantamento na escrita provam que a pobreza não lhes permite comprar papel”. ${ }^{12}$

De acordo com Daniel d'Araújo Valle, delegado do $3^{\circ}$ Círculo, muitos meninos não faziam progresso nas aulas públicas, porque "são filhos de Pais pobres, que lhes não podem fornecer papel, tinta, penas, e outros misteres, que são indispensáveis". ${ }^{13}$ Em visita à escola do distrito do Inficionado, o delegado do $2^{\circ}$ Círculo examinou dois meninos que estavam descalços e, em todas as outras visitas realizadas, constatou a falta de papel, penas e tinta. Salvador Machado de Oliveira, por sua vez, informava que no $11^{\circ}$ Círculo "alguns Pais me tem dado por desculpa das longas falhas de seus filhos, a nudez destes em consequência de pobreza". ${ }^{14}$

Reiterando as queixas de professores e delegados, o presidente Antonio da Costa Pinto (1837) falava à Assembleia Legislativa provincial sobre a necessidade de criar escolas, mas, sobretudo, de provê-las das condições necessárias para o processo de ensino-aprendizagem. Neste sentido, interrogava aos deputados: "que importa, que estes desgraçados frequentem as escola, se lhes falecem todos os meios para conseguirem a

10 Correspondências. Antonio Dias Abaixo, 18/10/1835 (APM SP PP 1/42, caixa 4, pacotilha 3).

${ }_{11}$ Ibidem. São Jose do Chopotó, 15/10/1836 (APM SP PP 1/42, caixa 4, pacotilha 35).

12 Ibidem. Minas Novas, 27/5/1836 (APM SP PP 1/42, caixa 5, pacotilha 47).

13 Ibidem. Sabará, 18/5/1837 (APM SP PP 1/42, caixa 8, pacotilha 8).

14 Ibidem. Campanha, 24/11/1838 (APM SP PP 1/42, caixa 12, pacotilha 37). 
Instrução Elementar?” (FALLA... 1837, p. VIII). Para estender a instrução elementar às populações pobres não bastava, apenas, criar escolas públicas e obrigar os pais a enviarem seus filhos às aulas; seria necessário fornecer aos meninos e meninas das diversas povoações aquilo que era indispensável à aprendizagem da leitura e escrita: papel, penas e tinta. $\mathrm{Na}$ tentativa de suprir tais carências, a Assembleia Legislativa provincial aprovou naquele mesmo ano a Lei Mineira n. 80, incorporando às despesas provinciais a compra e distribuição de objetos aos alunos pobres.

Embora os legisladores procurassem garantir o aproveitamento dos alunos e contornar parte dos problemas ocasionados pela pobreza das famílias, seus esforços ainda não eram suficientes para garantir o cumprimento do art. 12 da Lei Mineira n. 13. Em junho de 1836, Joze Pinheiro Neves, delegado do $7 .^{\circ}$ Círculo, encaminhava ao presidente da província o atestado do juiz de paz de Contendas e o requerimento de Martha Ribeira da Costa. Em seu atestado, o juiz de paz pedia orientações, pois não sabia como proceder frente a obrigatoriedade de instrução primária e a pobreza daquela mãe. Hesitante em intimar a mãe, o juiz de paz dizia que se não aplicasse a punição, deixaria de cumprir a lei; se multasse os pais de família pobres e que residiam distante das escolas, ofenderia a caridade; se os obrigasse a se justificarem, silenciaria a justiça, porque lhes faltavam os meios. Dessa forma, como poderia obrigá-los a enviar seus filhos à escola?

Entre as correspondências enviadas à presidência da província, a única justificativa para o não cumprimento do art. 12 da Lei Mineira n. 13 encontrada foi a de Martha Ribeira. Apesar da exclusividade desse requerimento, ele contempla a realidade de pobreza das famílias mineiras do século XIX e apresenta os outros obstáculos daí decorrentes.

Ilustríssimo Senhor Juiz de Paz

Diz Martha Ribeira da Costa parda viúva moradora no sitio d'Atoleiro, e agregada da fazendo da Tapera neste Distrito de Contendas, que fora notificada por ordem de V. S., para Lançar na Escola das primeiras Letras a seu filho Antonio de idade de 13 anos debaixo da pena de multa fulminada pela Lei. Esta aplicação tão necessária a cada um em particular, como digna da Nação em Geral, vai de encontro as forças morais da suplicante. 
$1^{\mathrm{o}}$ Porque mora seis léguas distante do Arraial, sede d'Aula, e tem a seu cargo duas filhas, sem outro algum meio de subsistência, além de Lavoura, se emprega esta pobre família composta de quatro indivíduos, sendo o mais útil o filho, apesar da tenra idade. Faltando ele a penúria é certa consequência $2^{\circ}$. A suplicante. faltam todos os meios, para manter aquele filho em qualquer aplicação: $3^{\circ}$. Prescindindo das razões alegadas, a suplicante.: pelo seu desvalimento não acha no Arraial, quem o admita em casa, e que vele sobre suas pueris ações, e más inclinações, de que é susceptível a natureza humana. Entregue o impúbere a descrição do tempo. Sem bride as suas paixões, muito mais depressa se entregará à corrupção, e imoralidade, que as lições ditadas pelo Professor, que de nada conhece fora da Aula. $4^{\mathrm{o}}$. Se a suplicante. se encarregar do penso, e da educação daquele filho junto ao assento da Escola, decerto lhe faltarão os meios para existir, e sua família: e por um só filho vem a perder todos. As razões expendidas não são ocultas a V. S., que está bem ao fato das continuadas precisões da desvalida suplicante, que nem meios tem, para pagar a despesa de uma prova Judicial de quanto tem levado dito. Se estas são as tristes circunstâncias, com que luta a desgraçada suplicante como há de pagar multa? Aonde há de ir por elas. Se a suplicante não acha proteção na Lei, sendo excluída do círculo do quarto de Légua marcado, em que se deve preencher os 500 indivíduos, para poder haver Professor público cujos habitantes talvez deverão ser os únicos compelidos com multa, oferece neste caso a V. Sa. a seu filho ao qual lhe dará o conveniente destino. Tendo lugar a negativa, como obediente filha da Lei, o vai apresentar a Matrícula do Professor, ficando a sustento, penso, e educação aventura.

Peço a Vossa Senhoria se digne definir com piedade, e equidade a pobreza da suplicante.

Não apenas no distrito de Contendas, mas em diversos outros locais, o trabalho era parte da rotina das crianças. Ida Lewkowicz e Horácio Gutiérrez (1999) informam que no termo da cidade de Mariana, aproximadamente, um terço das crianças trabalhava em diversas funções. Analisando o recenseamento de 1831, num total de quase 39.00o habitantes, os autores encontraram 8.803 crianças entre 5 e 14 anos. Destas, 1.109 eram livres e ocupavam-se em atividades de confecção (fiação, costura e rendas), de agricultura (lavoura e capina) e em ofícios como sapateiros, caixeiros, músicos, carpinteiros, mineiros, jornaleiros, tropeiros e ferreiros. Confecção e agricultura eram as ocupações mais comuns, sendo que esta última empregava quase exclusivamente meninos. 
A este respeito, o delegado do $2 .^{\circ}$ Círculo afirmava que no arraial de São Caetano havia muitas famílias pobres "que aproveitam serviços dos filhos, ainda que pequenos". ${ }^{15}$ No $12 .{ }^{\circ}$ Círculo, conforme o delegado Antonio Jose da Silva, "os Pais, salvas pequenas exceções, apenas os filhos sabem ler muito pouco, cuidam logo de emprega-los no serviço da lavoura, acanhando assim talentos, que podiam, cultivados, prestar grandes serviços a Pátria”. ${ }^{16}$ Com relação ao $15{ }^{\circ}$ Círculo, o delegado Antonio José Martins, dizia: “dos alunos matriculados os que não frequentam: o motivo é a pobreza de grande número, trabalhando muitos alguns dias da semana não só para se sustentarem, como para comprar papel: outros trabalhando nas roças com seus pais como com plantações, colheita, e mesmo alguns em capina." $17 \mathrm{O}$ delegado do 2. ${ }^{\circ}$ Círculo informava, ainda, que "quanto á execução do art. 12 da Lei n. 13 seja-me licito expor a Vossa Excelência que logo que entrei na tarefa, q. me foi confiada, tive algumas partes de Professores sobre as infrações, porém quando se querem dar as providências aparecem, não resistências, mas choradeiras de necessidades para colheitas de roças, cafés e outros". ${ }^{18}$

Outro obstáculo à frequência dos meninos à aula, como expresso no requerimento de Martha Ribeira, era a distância entre as escolas públicas e as casas das famílias. A escola mais próxima da casa de Antonio, filho de Martha Ribeira, ficava a seis léguas (39.6 k) de distância e para frequentá-la ele teria de residir em outro domicílio. Conforme declarava a requerente, na localidade onde estava a escola pública mais próxima não havia quem pudesse receber o menino e zelar por "suas pueris ações e más inclinações". Deixar os filhos sob o cuidado de educadores era prática recorrente para algumas famílias mineiras. Nos vários mapas de frequência e matrícula que os professores enviavam ao presidente da província de Minas Gerais, havia a preocupação em registrar o nome, a naturalidade e o domicílio do aluno; havia a preocupação, igualmente, em informar o nome do pai ou "educador" e seu domicílio. Embora nosso obje-

\footnotetext{
15 Correspondências. Mariana, 17/8/1835 (APM SP PP 1/42, caixa 3, pacotilha 16).

16 Ibidem. Uberaba, 8/8/1837 (APM SP PP 1/42, caixa 8, pacotilha 42).

17 Ibidem. Pouso Alegre, 18/12/1837 (APM SP PP 1/42, caixa 9, pacotilha 65).

18 Ibidem. Mariana, 6/11/1838 (APM SP PP 1/42, caixa 12, pacotilha 17).
} 
tivo não seja analisar essa prática, depreendemos que a indicação de domicílios diferentes para alunos e seus responsáveis, que não necessariamente eram seus pais, evidenciam mais uma das estratégias adotadas pelos pais de família para garantir a educação escolar de seus filhos. Em outra direção, a situação de Martha Ribeira, como descrita pelo juiz de paz, indica que, provavelmente, o pequeno número de escolas públicas se constituía como o maior obstáculo à generalização dos saberes elementares. Como relatava o delegado Reverendo Vigário Antonio Jose da Silva,

[...] compreendendo o $12^{\circ}$ Círculo mais de 90 léguas de cumprimento, e 40 de largura, e contendo para mais de 40:00o habitantes, pouco mais de 200 alunos se instruem nas escolas públicas, e particulares, já por que aquelas sendo só quatro, e estando muito distantes umas das outras, não bastão para o grande número de meninos, que há nos dois Municípios, Araxá, e Uberaba, já porque estas sendo ordinariamente pelas Fazendas, e então muito caro a alguns Fazendeiros, que, para darem a Instrução Primária a seus filhos, precisam, ou de pagar exorbitante quantia a um Mestre, ou de admitir, e sustentar em sua casa os filhos de seus vizinhos com incomodo considerável $[\ldots]^{19}$

Nas circunstâncias descritas, vemos que a lei da obrigatoriedade de instrução primária tinha seus limites. Diante de tantos impedimentos, como obrigar os pais de família a darem instrução aos seus filhos? Segundo aquele mesmo delegado: "para o cumprimento do Art. 12 da Lei Provincial n. 13, eu não me tenho poupado a frequentes advertências, mas devo confessar que me parece impossível a sua exata observância”. Nesta mesma direção, encontramos a seguinte orientação para o caso de Martha Ribeira:

Junho 28 Delegacia 7.

Em vista do Artigo 12 da Lei n. 13 de 28 de Março de 1835, e do Artigo $73 \S 5$. do Regulamento n. 3 de 22 de Abril do mesmo ano são plausíveis os motivos apresentados por Martha Ribeiro da Costa, reconhecidos verdadeiros pelo Senhor Delegado, que deverá, em quanto forem as desgraçadas as circunstâncias da Sobredita Martha não obriga-la a cumprir o que a Lei a tal respeito promove, visto ter a seu favor uma escassez da mesma Lei.

19 Ibidem. Uberaba, 18/11/1838 (APM SP PP 1/42, caixa 12, pacotilha 31). 
O pequeno número e a distância das escolas, a pobreza das famílias e a rotina de trabalho das crianças limitaram o acesso às aulas primárias e impediram a frequência regular de alunos. Daí alguns delegados e professores constatarem que "os pais dão quando podem educação aos seus filhos" 20 . Contrapondo-se às representações produzidas pelas elites mineiras, os documentos analisados permitem verificar que muitos pais se dedicaram, sim, ao cuidado e educação de seus filhos: não os sujeitando a situações que trouxessem riscos ao "amadurecimento de seu caráter", nem os privando da educação moral e profissional oferecida nas casas de família, nem mesmo deixando de oferecer-lhes, quando possível, a instrução primária.

\section{A atuação dos professores e o posicionamento das famílias}

A Lei Mineira n. 13 determinava que o ordenado dos professores fosse equivalente ao número de alunos frequentes. Assim, para assegurarem sua gratificação, os professores precisariam garantir a frequência escolar, fosse incentivando a matrícula e permanência das crianças na aula ou denunciando os pais de família "omissos". Todavia, como informava o delegado do $2^{\circ}$ Círculo, muitos professores públicos não ficaram satisfeitos com tal determinação.

De dia em dia estou a ouvir clamores de Professores de 1as. Letras pela diminuição do Ordenado que tinham, e aumento de trabalho com mapas semanais e pretendendo alguns demitirem-se, o resultado será ficar a mocidade em muitas partes privada daquela garantia que lhe prometeu a Constituição, acrescendo a bem disto o constituírem-se ou compelirem-se aos Professores a constituírem-se acusadores dos Pais que não mandarem os filhos à Aula, querendo antes perderem os Cômodos que sujeitarem-se ao Encargo tal. ${ }^{21}$

20 Ibidem. Diamantina, 1/12/1838 (APM SP PP 1/42, caixa 12, pacotilha 43).

${ }^{21}$ Ibidem. Mariana, 12/10/1835 (APM SP PP 1/42, caixa 3, pacotilha 68). 
Junto ao seu ofício, o delegado literário enviou o pedido de demissão do professor público da escola de primeiro grau do distrito de Arripiados. Em outro ofício o delegado informava que o professor de Cocaes também tinha a intenção de deixar a cadeira de instrução pública primária. Posicionando-se a favor dos professores, o delegado dizia que

Um Homem ocupado de manhã e de tarde em um Arraial não pode subsistir com menos de $300 \$$ e em Villas e Cidades com menos de 400\$. Se eu fora Autoridade Legítima assim o estabeleceria, porque o dizer-se que sendo fixo o Ordenado, não se cansam os Mestres pode-se dizer: Não sendo Capazes demitamse, e com a imposição da obrigação de acusar aos Pais pelas faltas dos filhos é o mesmo que dizer: não hajam Mestres: porque a maior parte dos Homens abominam aos que na forma comum são Denunciantes. Perdoe-me Vossa Excelência ultrapassar de alguma maneira, por um zelo que me anima, e o ver o desgosto dos Mestres com a diminuição dos ordenados me empenho a assim obrar, e posso afiançar-lhe que a pouca Civilização do nosso Pais faz com apareça o dizer uma May em resposta a uma Professora que exigia o motivo da falha que era por Sapatos, e passaram a dizer que o Zelo dos Mestres procede do desejo do aumento dos poucos reis. ${ }^{22}$

Antonio Emilio Gomes, como aqueles dois outros professores, manifestou ao delegado literário seu descontentamento com as determinações do governo provincial. Segundo esse professor, se os pais e as próprias autoridades locais não queriam cumprir a lei, "deque meios me valerei para reduzir a se matricularem muitos meninos que há neste contorno?". ${ }^{23}$ Desagradar aos pais de família e às autoridades locais ocasionaria uma série de inconvenientes: em decorrência de boatos sobre a conduta do professor e da ameaça do recrutamento, os pais de família poderiam deixar de mandar seus filhos à aula; o descontentamento da população, por outro lado, levaria o governo provincial a demitir ou transferir o professor público para outra localidade. Em março de 1836, o delegado do $2^{\circ}$ Círculo comunicava ao presidente da província o descontentamento da população do distrito de Ponte Nova com o professor público de primeiras letras, Floriano Jose de Oliveira. Convencido da neces-

22 Ibidem. Mariana, 15/9/1835 (APM SP PP 1/42, caixa 3, pacotilha 44).

23 Ibidem. Antonio Dias Abaixo, 18/10/1835 (APM SP PP 1/42, caixa 4, pacotilha 3). 
sidade de demiti-lo, o delegado afirmava ser a sua inaptidão a causa da frequência de poucos alunos, "sendo certo de que se fosse bom Mestre os Pais, concorreriam com muito gosto para que seus filhos não faltassem, e os outros se aproveitassem". ${ }^{24}$ Acompanhando o relatório desse delegado encontramos um ofício do professor Floriano Jose, em que denunciava os pais por retirarem seus filhos da escola e depois os matricularem novamente para "acabarem de aprender". Em seu ofício esse professor apresentou uma lista com os nomes de pais que "fazem seus filhos falharem demais na Escola da nação" e outra com os nomes daqueles que "por omissos ainda os não puseram na Escola”.

No intuito de verificar se o problema da infrequência era a falta de habilidade do mestre ou a omissão dos pais, o delegado literário visitou a escola e enviou ao presidente o seguinte parecer:

Na tarde do dia 28 em visita achei 19 Alunos, entre os quais só estava um calçado, mostrando os outros bastante pobreza Confesso a Vossa Excelência que me compadeci bastantemente do estado do Professor pois que é casado, com grande família, sem outro meio de vida, e por conseguinte sofrendo grandes faltas, é incansável no exercício cumprindo a risca as horas do ensino, porém uma Má Estrela o Preside, pois que todos os habitantes do Arraial são uniformes em dizer: Cansa-se, mas não dá um só Discípulo pronto, e não tem uma só Menina ao presente. Por conseguinte, tendo-me ele dado a resposta junta com o atestado do Juiz de Paz, e dando o Reverendo Pároco que é o meu visitador a outra sobre o exercício acho-me bastantemente vacilante em cumprir a última parte do ofício, ou Portaria de Vossa Excelência pois que para um lado encontro o que refiro, e para o outro a esperança de que os melhores Distriteanos não lhe dão os filhos, parecendo-me que se pode conciliar de alguma maneira em ser transferido para Arripiados a começar no futuro Janeiro, e considerar-se vaga a Cadeira da Ponte Nova para se pôr a concurso em dezembro, e quando ele não queira aceitar queixe-se da sua má Sorte em ter desagradado aos Pais de famílias do lugar onde existe. 25

Tanto o pároco quanto o juiz de paz de Ponte Nova, atestavam o bom comportamento e desempenho de Floriano Jose. Segundo informa-

\footnotetext{
24 Ibidem. Mariana, 7/3/1836 (APM SP PP 1/42, caixa 5, pacotilha 13).

25 Ibidem. Mariana, 2/7/1836 (APM SP PP 1/42, caixa 5, pacotilha 62).
} 
va o juiz de paz, esse professor "tem residido sempre formal, e materialmente na Escola do seu Magistério, e não consta que tenha escandalizado com o seu exemplo aos alunos do seu ensino, antes os tem tratado com respeito devido como é próprio do seu caráter”. ${ }^{26}$ Não obstante tivesse um comportamento "exemplar", o descontentamento dos pais de família motivaria a remoção do professor. ${ }^{27}$ Floriano Jose foi removido em junho de 1839, três anos após enviar a lista de "pais omissos" ao delegado literário. A análise da documentação leva a crer que teriam sido as denúncias do professor o motivo para que as autoridades locais indicassem ao delegado, reiteradas vezes, a insatisfação dos pais de família. Em outra direção, o que teria possibilitado a permanência desse professor por mais três anos na cadeira de instrução pública? Nas correspondências posteriores ao mês de março de 1836, enviadas à secretaria da presidência pelo delegado do $2^{\circ}$ Círculo, encontrei informações sobre o aumento da frequência na escola de Ponte Nova (de 19 alunos em 1836, para 38 em 1838); sobre o fato de Floriano Jose ter sido habilitado no método de ensino mútuo, quando esteve na escola de Ouro Preto; sobre o exame público de seus alunos, em 1837, quando oito deles foram "encontrados com aproveitamento". Os resultados apresentados por Floriano Jose garantiram seu título de professor de primeiras letras, mas não foram suficientes para convencer os pais de família de que possuía as competências necessárias para permanecer na escola de Ponte Nova.

Na documentação analisada foram recorrentes as referências à insatisfação da população quanto à conduta e à competência de mestres de primeiras letras. Em setembro 1836, o delegado do $2^{\circ}$ Círculo comunicava à presidência da província sobre o pouco zelo do professor da escola da vila de Itabira, Joaquim R. Neves. Segundo o delegado, esse professor não havia mandado buscar os papéis para os alunos pobres e dava suetos sem antes consultá-lo. ${ }^{28}$ Em agosto de 1837, ao visitar a escola, o delegado foi informado por "conceituados cidadãos" que o professor era "pés-

\footnotetext{
${ }^{26}$ Ibidem. Ponte Nova, 29/6/1836 (APM SP PP 1/42, caixa 5, pacotilha 62).

27 Ibidem. Mariana, 1/6/1839 (APM SP, códice 233).

28 Ibidem. Mariana, 21/9/1836 (APM SP PP 1/42, caixa 6, pacotilha 25).
} 
simo" e, por isso, muitos pais preferiam pagar pelas aulas do mestre particular. Todavia, informava o delegado que apesar dos

[...] defeitos do Professor no Livro de Matricula, e outros mais, ainda que pequenos de falta de educação, e método de viver com o Povo achei os Alunos com princípios próprios conforme suas idades, e tempos de exercício, e alguns com aproveitamento, e por isso não se pode dizer mau Mestre, sim que tem muita Gente ao seu encargo, assistindo ao exame 70 Alunos [...].29

Neste mesmo relatório, o delegado dizia que, com relação à escola de Inficcionado, os alunos encontravam-se muito "defeituosos" na leitura e contas. Nas margens desse documento foram anotadas, então, algumas das providências que deveriam ser tomadas pelo delegado literário. Provavelmente redigidas pelo presidente da província, a quem eram endereçadas as correspondências, essas anotações orientavam o delegado a

Constantemente informar-se da conduta dos Professores negligentes e particularmente dos de Itabira e Inficcionado [...] fazendo-lhes ver, que se seu Comportamento para com os alunos não merecer a aprovação do público sensato, e principalmente dos pais de família, que mais, do que quaisquer outras pessoas, estes anseiam de apreciar os progressos de seus filhos [...] serão demitidos ou removidos.

Salvador Machado de Oliveira, delegado suplente do $11^{\circ}$ Círculo, apresentou ao presidente da província, em fevereiro de 1838, a queixa de um pai que teve o filho castigado num sábado "com duas dúzias e nove palmatoadas; e no outro Sábado seguinte voltara a sofrer outras nove, cujos castigos lhes foram infligidos, para obrigá-lo a compreender o que estudava, como sendo contas". ${ }^{30}$ Entre os documentos apresentados pelo delegado encontramos, ainda, o oficio que ele enviou ao professor Jose Antonio Rodrigues Mendes, atestando o recebimento de outras acusações e orientando-o sobre o uso da palmatória.

Havendo assim mais acusações a seu respeito, como quando, toma as lições dar empurrões nos Alunos puxar, e levanta-los

\footnotetext{
29 Ibidem. Mariana, 1/8/1837 (APM SP PP 1/42, caixa 8, pacotilha 60).

30 Ibidem. Campanha, 24/2/1838 (APM SP PP 1/42, caixa 10, pacotilha 39).
} 
pelas Orelhas, feri-las com unhadas, ter quebrado a Cabeça de um com a Palmatoria e gritar muito; cujas informações que tomei sendo-lhes desfavoráveis, cumpre-me significar-lhe: que com quanto se julgue indispensável que os Mestres de $1^{\mathrm{a}}$ Letras usem a Palmatoria, cuja disposição Legislativa não sendo explicita, por minha exigência o Excelentíssimo Governo da Província interpretou no meu sentido; todavia estou intimamente convencido que o castigo físico da Palmatória deve ser além de moderado, aplicado ao Menino, quando é turbulento na Escola, não obedece a seu Mestre, ou o desatende; e nunca jamais quando ele por falta de boa compreensão lhe custa muito aprender; porque semelhante castigo neste caso somente daria em resultado o atiçamento, e por fim estupidez; sendo o único meio de os fazer compreender a explicação reiterada e maneiras dóceis do Mestre. ${ }^{1}$

Certificando-se da imprecisão do dispositivo legal, que permitia aos professores corrigir moderadamente seus alunos, ${ }^{32}$ o delegado reconhecia que as punições deveriam ser aplicadas em relação aos atos de indisciplina e graduadas conforme a "idade do paciente, e a natureza do crime”. Diva do Couto Gontijo Muniz (2002), discutindo a escolarização de meninos e meninas no século XIX, afirma que a postura autoritária e violenta de alguns professores era uma estratégia para compensar sua falta de habilidade para o magistério. Argumento este confirmado pelo delegado literário que considerava os maus tratos infligidos pelo professor "impensados" e "arrebatadores" e, ainda, incorretos, pois se punia "a falta de boa compreensão" ao invés de contorná-la com a "explicação reiterada" e com "maneiras dóceis".

Apesar da severidade do professor na aplicação dos castigos, a escola pública primária da vila de Campanha possuía um grande número de meninos e meninas. No mapa de escolas apresentado pelo delegado do $11^{\circ}$ Círculo, em 1838, vemos que a aula do professor Jose Antonio era frequentada por, aproximadamente, 159 alunos.33 Diferentemente do que aconteceu no distrito de Ponte Nova - onde o professor público denunciou a omissão dos pais de família -, nas vilas de Itabira e Campanha os professores permaneceram ocupando a cadeira de instrução primária,

${ }^{31}$ Ibidem. Campanha, 16/2/1838 (APM SP PP 1/42, caixa 10, pacotilha 39).

$3^{2}$ Lei Mineira n. 13 de 29/3/1835. Art. $39^{\circ}$ e $40^{\circ}$.

33 Correspondências. Campanha, 5/4/1838 (APM SP PP 1/42, caixa 10, pacotilha 57). 
mesmo que sob a ameaça de demissão. Nessas duas últimas localidades, o constante e elevado número de alunos frequentes rendeu alguma credibilidade aos professores. Como dizia Jose Antonio, frente às queixas de alguns habitantes havia o "consolo" do número de alunos aumentar cada vez mais. 34

Ainda sobre o professor Floriano Jose de Oliveira, encontramos outras informações e o indicativo de que as constantes remoções, demissões e substituições de professores públicos interferiram na rotina do trabalho escolar e caracterizaram as relações estabelecidas entre os pais de família, as escolas públicas e seus professores. Floriano Jose foi removido da escola pública de Ponte Nova para o distrito de Barra do Bacalhau. Chegando à escola dessa localidade, o professor se deparou com a "falta de alunos" e, para não perder seu emprego, teve a iniciativa de matricular em sua aula doze meninas; a instrução dessas meninas seria de responsabilidade de Anna Felícia R. de Oliveira, a quem o professor pagaria pelo trabalho. 35 A presença de uma mulher na aula garantiu a matrícula de meninas, no entanto, por que os pais de família confiariam a instrução de seus filhos e filhas a um estranho?

Entre os anos de 1835 e 1840, a cadeira de instrução primária de Barra do Bacalhau foi ocupada por quatro professores: Francisco de Paula Duarte Leitão, José Venâncio de Godoy, João Alves de Almeida França e Floriano José de Oliveira. João Alves de Almeida França foi professor em Barra do Bacalhau de 1837 a 1839. Antes de ocupar a cadeira de instrução pública dessa localidade, esse mesmo professor já havia passado pela escola primária do distrito de São Bartolomeu e, nesta localidade, segundo o delegado literário, também não havia merecido a "simpatia do povo" 36 . Num levantamento preliminar (tabela 1 ), para as escolas do $2^{\mathbf{o}}$ Círculo Literário, pude constatar o deslocamento de professores por diferentes distritos e o número elevado de demissões.

\footnotetext{
34 Ibidem. Campanha, 19/2/1838 (APM SP PP 1/42, caixa 10, pacotilha 57). 35 Ibidem. Mariana, 13/6/1839 (APM SP PP 233, APM).

${ }^{6} 6$ Ibidem. Mariana, 5/5/1839 (APM SP 233, APM).
} 
Tabela 1 - 2. ${ }^{\circ}$ Círculo Literário: demissões, remoções, licenças e substituições de professores públicos primários - 1835-184037. Fonte: Correspondências. 1835-1840 (APM SP PP 1/42, caixas 1 a 13).

\begin{tabular}{lcccc}
\hline \multicolumn{1}{c}{ Localidades } & Demissões & Remoções & Licenças & Substituições \\
\hline Antonio Dias Abaixo & $\ldots$ & $\ldots$ & $\ldots$ & $\ldots$ \\
Antonio Pereira & 1 & $\ldots$ & 1 & $\ldots$ \\
Arripiados & 3 & $\ldots$ & $\ldots$ & 2 \\
Barra do Bacalhau & 2 & 1 & $\ldots$ & $\ldots$ \\
Barra Longa & 1 & $\ldots$ & $\ldots$ & $\ldots$ \\
Bento Rodrigues & $\ldots$ & $\ldots$ & $\ldots$ & $\ldots$ \\
Brumado & 1 & $\ldots$ & $\ldots$ & 1 \\
Catas Altas & $\ldots$ & $\ldots$ & 3 & 2 \\
Cocaes & 1 & $\ldots$ & $\ldots$ & 1 \\
Cuiete & 1 & 1 & $\ldots$ & 1 \\
Espera & $\ldots$ & $\ldots$ & 1 & $\ldots$ \\
Furquim & $\ldots$ & $\ldots$ & $\ldots$ & 1 \\
Guara Piranga & 2 & $\ldots$ & 1 & 2 \\
Inficcionado & 1 & $\ldots$ & 1 & 2 \\
Itabira & 1 & $\ldots$ & 1 & $\ldots$ \\
Mariana & $\ldots$ & $\ldots$ & $\ldots$ & $\ldots$ \\
Passagem & 1 & $\ldots$ & $\ldots$ & 1 \\
Paulo Moreira & $\ldots$ & $\ldots$ & $\ldots$ & $\ldots$ \\
Ponte Nova & $\ldots$ & 1 & $\ldots$ & 1 \\
Santa Bárbara & $\ldots$ & $\ldots$ & $\ldots$ & $\ldots$ \\
Santa Cruz & $\ldots$ & $\ldots$ & $\ldots$ & $\ldots$ \\
Santa Anna dos Ferros & $\ldots$ & $\ldots$ & $\ldots$ & $\ldots$ \\
São Caetano & $\ldots$ & $\ldots$ & $\ldots$ & $\ldots$ \\
São Domingos do Prata & $\ldots$ & $\ldots$ & $\ldots$ & $\ldots$ \\
São João do Morro Grande & $\ldots$ & $\ldots$ & $\ldots$ & $\ldots$ \\
São Jose do Chopoto & $\ldots$ & $\ldots$ & $\ldots$ & $\ldots$ \\
São Miguel & $\ldots$ & $\ldots$ & $\ldots$ & $\ldots$ \\
Saúde & $\ldots$ & $\ldots$ & $\ldots$ & $\ldots$ \\
Sumidouro & $\ldots$ & $\ldots$ & $\ldots$ & $\ldots$ \\
\hline & $\ldots$ & $\ldots$ & $\ldots$ & $\ldots$ \\
\hline & $\ldots$ & $\ldots$ & $\ldots$ & $\ldots$ \\
\hline
\end{tabular}

Para os anos de 1835 a 1840, no 2. ${ }^{\circ}$ Círculo Literário, 21 professores foram demitidos. Alguns desses professores chegaram a encaminhar

37 Não considerei aqui os dados relativos às duas escolas de meninas do $2 .{ }^{\circ}$ Círculo Literário. 
ao governo seu pedido de demissão, alegando terem sido nomeados para ocupar outro cargo; outros professores foram demitidos, em consequência da insatisfação dos habitantes das povoações. A opinião dos pais de família, a respeito dos professores primários, como temos constatado, possuía grande relevância para as autoridades provinciais. A Lei Mineira n. 13 estipulava que cabia ao governo, conforme as informações dos delegados literários, suspender, demitir e remover professores públicos. ${ }^{38} \mathrm{E}$, como pude observar, no conjunto da documentação, a intervenção dos pais de família, muitas vezes, era definitiva para a remoção, demissão ou permanência dos professores nas escolas primária. Nesta perspectiva, da mesma forma que a insatisfação da população poderia trazer prejuízos aos professores primários, ser "rogado" ou "conhecido" dos pais de família constituía-se num requisito importante para o preenchimento das cadeiras de instrução primária.

De acordo com o delegado do $2^{0}$ Círculo, no distrito de Arripiados, desde que o professor Leovigildo Justinianno da Silva assumiu a cadeira de instrução pública, "os Alunos pouco, a pouco foram desamparando a Aula a ponto de se ver o Mestre apenas com dois ou três".39 O delegado não sabia ao certo se o motivo das falhas era a incapacidade do professor ou, como este alegava, as intrigas do juiz de paz que "aliciava" os pais para não enviarem os filhos à aula, a fim de terem outro mestre. Em resposta às requisições do delegado e com o intuito de dar seu parecer sobre a situação, o visitador parcial da escola informava que o professor era pouco "assíduo" e "não mereceu o conceito dos Pais de família" que, progressivamente, retiraram seus filhos da escola.40 A cadeira pública de instrução primária de Arripiados foi ocupada, então, em fevereiro de 1838, por João Joaquim de Figueiredo. Este professor permaneceu no cargo até maio do mesmo ano, quanto foi nomeado escrivão do juiz de paz. Novamente a escola precisava ser provida e o governo provincial resolveu reintegrar o antigo professor dessa localidade: Venâncio Jose da Silva Tinoco. Nas palavras do delegado literário: "este Professor é bom Homem, e es-

\footnotetext{
${ }^{38}$ Lei Mineira n. 13. 29/3/1835. Art. $21^{\circ}, 22^{\circ}$ e $23^{\circ}$.

39 Correspondências. Mariana, 1/12/1837 (APM SP PP 1/42, caixa 9, pacotilha 57).

40 Ibidem. Arripiados, 24/9/1837 (APM SP PP 1/42, caixa 9, pacotilha 58).
} 
pero que concorram muitos Alunos por ser conhecido no lugar, e haver sido rogado por alguns Pais de família para ser encarregado de tal tarefa”. 41

Em todas as situações apresentadas, menos que oposição entre família e escola, vemos relações de negociação, no sentido de promover condições mais adequadas para a educação das crianças; e estas relações não se fizeram sem conflitos e tensões, sem recusas e adaptações. Assim, compreendo que as famílias tiveram um importante papel na legitimação da escola como espaço de formação das novas gerações e na redefinição das medidas adotadas pelo governo mineiro no processo de escolarização da província. Partindo destas constatações é possível concluir que as situações vividas entre as famílias, as escolas e o governo caracterizaramse, sobretudo, como relações de negociação, no sentido de promover condições consideradas mais adequadas à educação das crianças. As intenções de muitos pais de família, nesse sentido, assemelhavam-se às dos dirigentes mineiros que viam na instrução pública um caminho possível para a participação - mesmo que controlada - naquela "civilização principiante”.

Essas constatações permitem problematizar a perspectiva adotada por pesquisadores e educadores de que a escola ao longo de sua história serviu, acima de tudo, como instrumento de controle e dominação. Marcus Vinícius da Cunha (2000), no texto A escola contra a família, propôs discutir a relação entre essas duas instituições numa perspectiva histórica; fundamentou-se para isto em discursos de educadores como Comênio, Lourenço Filho, Fernando de Azevedo, Anísio Teixeira e em artigos publicados, na primeira metade do século XX, em revistas brasileiras. Para Cunha, no "momento áureo" de elaboração dos modelos educacionais contemporâneos, o século XVII, a escola foi pensada como agência de apoio à família. No entanto, ao longo de sua evolução, ela tornou-se mais do que uma simples instituição de apoio, posicionando-se "contra" a família (CUNHA, 2000, p. 450). E o que fomentou esta oposição, segundo o autor, foi a incorporação de saberes científicos às práticas e roti-

${ }^{41}$ Ibidem. Mariana, 29/8/1838 (APM SP PP 1/42, caixa 11, pacotilha 67). 
nas escolares, uma vez que "o discurso da ciência caracteriza-se por desqualificar a família no tocante à educação do corpo e do espírito”:

Psicólogos, pediatras, assistentes sociais e professores sabem mais do que pais, avós, tias... Isto é o que vem sendo sustentado em toda a história da escola, e é a mentalidade que vigora nos dias de hoje. Se não fosse assim, como justificar que as palestras desses profissionais sejam tão insistentemente programadas pelas direções das escolas nas reuniões de pais e mestres, e tão bem recebidas por todos os que as frequentam? Esse exemplo banal serve para que pensemos no status que têm os saberes científicos não só quanto ao "como ensinar", mas sobretudo ao "como educar". (CUNHA, 2000, p. 450) [Grifo meu]

Partindo desta afirmação, Cunha fez uma reflexão em torno da cientifização da escola - movimento empreendido por médicos higienistas, no século XIX - e do consequente combate às características culturais das famílias brasileiras. Tratou da influência das ciências sociais, no início do século XX, na renovação desse ideal da escola cientificizada. Falou das discussões promovidas nos Centros de Pesquisas Educacionais, a partir da década de 1950, sobre a necessidade de normalizar as escolas para o trabalho com as populações pobres. $\mathrm{E}$ disse, finalmente, que as teorias sobre "deficiência cultural" e "educação compensatória", adotadas pelos educadores dos anos de 1960 e 70, desqualificaram e responsabilizaram as famílias pobres pelo fracasso e evasão escolar. Tendo em vista as fontes e os argumentos aos quais recorreu, é impossível não considerar a história da escola como sendo a da legitimação de um espaço educativo específico em detrimento das experiências formativas vivenciadas no interior das famílias.

No entanto, ao me aproximar dos discursos produzidos pelos pais de família, professores e fiscais pude perceber que o "ímpeto normalizador" (CUNHA, 2000, p. 449) da instituição escolar não atingiu - nas primeiras décadas do século XIX, em Minas Gerais - as famílias com aquela intensidade atribuída por Cunha. Naquele tempo e espaço, muitas pessoas manifestaram interesse na existência e funcionamento das escolas públicas primárias e participaram - mesmo quando se recusavam a enviar as crianças às aulas - da definição dos tempos, espaços, saberes e práticas 
escolares. É inegável a centralidade assumida pela escola no decorrer dos séculos XIX e XX e indiscutível sua diretiva homogeneizadora frente às populações pobres; mas essa legitimidade foi sendo construída, sobretudo, a partir de um jogo de forças - nem sempre equilibrado - entre diferentes agentes e instâncias educativas. Por isso, é preciso considerar que os pais de família, bem como os professores, fiscais e legisladores, assistiram à consolidação de um modelo escolar de educação e contribuíram, à sua maneira, para o reconhecimento das escolas primárias como lugares privilegiados para a formação das novas gerações.

\section{Referências}

CUNHA, M. V. A escola contra a família. In: LOPES, E. M. T.; FARIA FILHO, L. M.; VEIGA, C. G. (org.). 500 anos de educação no Brasil. Belo Horizonte: Autêntica, 2000, p. 447- 468.

DUARTE, R. H. Noites circenses. Espetáculos de circo e teatro em Minas Gerais no século XIX. Campinas: Editora da UNICAMP, 1995.

ELIAS, N. O processo civilizador: uma história dos costumes. Rio de Janeiro: Jorge Zahar, 1994.

FARIA FILHO, L. M. A legislação escolar como fonte para a História da Educação: uma tentativa de interpretação. In: Educação modernidade e civilização: fontes e perspectivas de análise para a história da educação oitocentista. Belo Horizonte: Autêntica, 1998, p. 89- 125.

. Estado, cultura e escolarização em Minas Gerais no século XIX. In: VIDAL, D. G.; SOUZA, M. C. C. (org.). A memória e a sombra: a escola brasileira entre o Império e a República. Belo Horizonte: Autêntica, 1999, p. 117-136.

FARIA FILHO, L. M.; GONÇALVES, I. A. Processo de escolarização e obrigatoriedade escolar: o caso de Minas Gerais (1835-1911). In: FARIA FILHO, L. M. (org.) A infância e sua educação. Materiais, práticas e representações [Portugal e Brasil]. Belo Horizonte: Autêntica, 2004, p. 159187. 
FIGUEIREDO, L. R. A. Barrocas famílias: vida familiar em Minas Gerais no século XVIII. São Paulo: HUCITEC, 1997.

INÁCIO, M. S. O processo de escolarização e o ensino de primeiras letras em Minas Gerais (1825-1852). Dissertação (Mestrado) - Universidade Federal de Minas Gerais, Belo Horizonte, 2003.

JINZENJI, M. Y. A escolarização da infância pobre nos discursos educacionais em circulação em Minas Gerais (1825-1846). Dissertação (Mestrado) - Universidade Federal de Minas Gerais, Belo Horizonte, 2002.

LEWKOWICZ, I.; GUTIERREZ, H. Trabalho infantil em Minas Gerais na primeira metade do século XIX. Locus, v. 5, n. 2, p. 9-21, 1999.

MARTINS, M. C. S. Revisitando a província: comarcas, termos, distritos e população de Minas Gerais em 1833-35. In: Anais do Seminário sobre a Economia Mineira. Belo Horizonte: UFMG/CEDEPLAR, 1990, p. 1329.

MUNIZ, D. C. G. Construindo diferenças: a escolarização de meninos e meninas nas minas oitocentistas (1834-1889). In: Anais do Congresso Mineiro de História da Educação. Belo Horizonte: FCH/Fumec, 2002, p. 298-319.

PERROT, M. Figuras e papéis. In: PERROT, M. et al (org.). História da vida privada: da Revolução Francesa à Primeira Guerra. São Paulo: Companhia das Letras, 1991. 4 v. p.121-185.

SEGALEN, M. A revolução industrial: do proletário ao burguês. In: História da família. O ocidente: industrialização e urbanização. Portugal: Terramar, 1999.

VEIGA, C. G. História Política e História da Educação. In: FONSECA, T. N. L.; VEIGA, C. G. (org.). História e historiografia da educação no Brasil. Belo Horizonte: Autêntica, 2003, p. 13-47.

\section{Fontes}

BRASIL. Coleção das Leis do Império. Disponível em <www.camara.gov. br>. Acesso em: 10 jun. 2017.

CARVALHO, F. Instrução Pública - Estudo Histórico e Estatístico das Primeiras Aulas e Escolas de Minas Gerais (1721-1860). Revista do Arquivo Público Mineiro, Belo Horizonte, ano XXIV, v. 1, 1933.

CORRESPONDÊNCIAS RECEBIDAS PELA PRESIDÊNCIA DA PROVÍNCIA. 1823-1852. SP (Seção Provincial), PP (Presidência da Província) $1 / 42$ caixas de 01 a 14 . APM. 
SP, códices 232-236. APM.

FALAS DIRIGIDAS À ASSEMBLÉIA LEGISLATIVA PROVINCIAL DE MINAS GERAIS PELOS PRESIDENTES DA PROVÍNCIA. 1838-1850. Disponível em: <http://www.crl.edu/catalog/index.htm>. Acesso em: 10 jun. 2017.

MINAS GERAIS. Livro da Lei Mineira. APM.

O UNIVERSAL. Ouro Preto. 1825-1842. APM.

Recebido em o5 de maio de 2017. Aprovado em 02 de junho de 2017. 